\title{
A Hybrid Monte Carlo and Possibilistic Approach to Estimate Non-suppression Probability in Fire Probabilistic Safety Analysis
}

\author{
Wei Wang ${ }^{1}$, Francesco Di Maio ${ }^{1}$, Piero Baraldi ${ }^{1}$, Enrico Zio ${ }^{1,2}$ \\ ${ }^{1}$ Energy Department, Politecnico di Milano, Via La Masa 34, 20156 Milano, Italy \\ ${ }^{2}$ Chair on System Science and the Energy Challenge, Fondation Electricite' de France (EDF), CentraleSupélec, Université \\ Paris-Saclay, Grande Voie des Vignes, 92290 Chatenay-Malabry, France \\ e-mail: wei.wang@polimi.it, francesco.dimaio@polimi.it, piero.baraldi@polimi.it, enrico.zio@polimi.it
}

\begin{abstract}
In Fire Probabilistic Safety Analysis (FPSA), the non-suppression probability (that quantifies the likelihood that the installed protection system fails to protect the target from fire) is typically estimated using predefined detectionsuppression event trees, that are expected to cover uncertainties with conservatism. In this study, a hybrid Monte Carlo (MC) and possibilistic approach is proposed for uncertainty propagation and effective quantification of a protection system non-suppression probability. In particular, aleatory uncertainty is represented by probabilistic distributions and treated by MC sampling, whereas, epistemic uncertainty of human behavior by means of possibility distributions.

The approach is applied to a switchgear room of a Nuclear Power Plant (NPP). Uncertain responsiveness of the fire protection system is integrated into a detection-suppression event tree, allowing for a clearer modeling interpretation and a more accurate failure probability estimate.
\end{abstract}

Keywords-Fire Probabilistic Safety Analysis (FPSA); fire non-suppression probability; aleatory uncertainty; epistemic uncertainty; possibility distribution

\section{INTRODUCTION}

The report "Fire Probabilistic Safety Analysis (PSA) Methodology for Nuclear Power Facilities (EPRI 1011989, NUREG/CR-6850, Final Report)" was issued to guide the fulfillment of fire PSA for commercial Nuclear Power Plants (NPPs) with state-of-the-art methods, tools and data [1]. Therein, Task 11 "Detailed Fire Modeling" describes models for fire growth and propagation (especially for the riskrelevant compartments) and frequency estimation of scenarios in which fire protections fail to protect a target. In general, with respect to a generic fire scenario $S$, its frequency of occurrence $F$ can be expressed as:

$$
F=\left(\sum_{i} \lambda^{i, S} \cdot G^{i}\right) \cdot S F \cdot P_{N S}
$$

where $\lambda^{i, S}$ is the fire ignition frequency due to the $i$-th ignition source present in the considered fire compartment $[1,12] ; G^{i}$ is a geometric factor adjusting the $i$-th ignition frequency $\lambda^{i, S}$ to a specific area of the compartment that might be affected by the ignition which takes into account the different locations or/and orientations of the ignition source; $S F$ is the severity factor representing the probability that, given ignition, the fire achieves the minimum size required to damage the risk-relevant target and, can be calculated by using a heat release rate probability density function $[1,17,18] ; P_{N S}$ is the non-suppression probability of the fire scenario, which quantifies the likelihood that the installed protection systems fail to protect the target from the ignited fire. To account for the uncertainties of the fire propagation process, the method reported in Appendix $\mathrm{P}$ of [1] is commonly employed.

In a specific fire scenario, the estimate of $P_{N S}$ is affected by two types of uncertainties: (1) aleatory uncertainty due to inherent variability in the system behaviors, such as physical properties of the ignition sources, responses of the automatic protection systems, etc., and, (2) epistemic uncertainty due to lack of knowledge and action imprecision on the system, for example, human errors in manual protection measurements [2-4].

Aleatory and epistemic uncertainties can be treated by a hybrid Monte Carlo (MC) and possibilistic approach [3, 5, 6, 13]. In particular, aleatory uncertainty related to randomness is modeled with MC sampling from probability distributions, whereas, epistemic uncertainty due to imprecise knowledge is treated by possibility theory, using possibility and necessity measures obtained from expert judgment. The approach has proven to be effective for jointly propagating the aleatory and epistemic uncertainties in a risk model [5]. In this study, with respect to the fire non-suppression analysis of a fire scenario, we propose the hybrid Monte Carlo and possibilistic approach to propagate aleatory uncertainty (affecting fire growth and propagation, and response time of the automatic protection system) and epistemic uncertainty (related to human behavior). Probability distributions of the aleatory variables (i.e., the response time of automatic actuation systems) are obtained from a detailed fire scenario modeling in Fire Dynamic Simulator (FDS) [4, 7, 8], whereas, possibility distributions (i.e., the Performance Shaping Factors (PSFs) affecting the human actions) are elicited from a Standardized Plant Analysis Risk-Human Reliability Method (SPAR-H) model [9-11]. Both probability and possibility distributions, being factors of the non-suppression probability, are integrated into the suppression-detection event tree, allowing for the quantification (with confidence) of the system failure probability. 
The reminder of the paper is organized as follows. Section II presents the case study: the main characteristics of a NPP switchgear room and its FDS fire modeling. In Section III, a SPAR-H analysis of the manual protection actions is performed, to define the possibility distributions of the PSFs. In Section IV, responses of automatic and manual protection systems are combined into a generic detectionsuppression event tree, to estimate the fire non-suppression probability of a fire in the switchgear room. Section V draws the conclusions.

\section{CASE StUdy}

Switchgear rooms (equipped with cabinets and cables) are very important for the normal operation of safety-related systems [12], and, therefore, many efforts are devoted to fully quantify the fire risk in switchgear rooms resorting to FPSA. In this study, the reference room is assumed to be normally closed as shown in Figure 1 [12], where twelve power distribution cabinets are symmetrically distributed on the two sides of the room and, the cables are distributed in the cabinets and in the cable trays under the steel floor. Geometric parameters and physical properties values of the room are listed in Tables I and II, respectively. Automatic protection devices are installed in the center of the ceiling, i.e., one heat detector, one smoke detector and one automatic sprinkler. Once a fire occurs, successful detection of the smoke detector or/and the heat detector can, on one hand, actuate the automatic sprinkler to control the fire in a delay time around 0.2 minutes, and on the other hand, alarm the main control room, to call the response of a fire brigade (whose response time is $0.5 \sim 1$ hour [14]). The fire also can be promptly detected and controlled thanks to an on-site fire man by using the fire extinguisher outside the room.

TABLE I. VAlues of GeOMetric Parameters of FDS MOdeling

\begin{tabular}{|c|c|c|c|c|}
\hline \multirow{2}{*}{ Category } & \multicolumn{4}{|c|}{ Input parameters } \\
\cline { 2 - 5 } & Number & Width $[\mathbf{m}]$ & Depth $[\mathbf{m}]$ & Height [m] \\
\hline Room & 1 & 5.0 & 6.0 & 3.6 \\
\hline Door & 1 & 1.5 & $\backslash$ & 2.2 \\
\hline Cabinets & 12 & 0.7 & 1.0 & 2.0 \\
\hline
\end{tabular}

TABLE II. VAlues of Physical Parameters of FDS MOdeling

\begin{tabular}{|c|c|c|c|c|}
\hline Category & Paint & Cable & \multicolumn{2}{|c|}{ Wall } \\
\hline \multirow{3}{*}{ Material } & \multirow{3}{*}{$\begin{array}{l}\text { Flame } \\
\text { retardant }\end{array}$} & \multirow{3}{*}{ PVC } & Ceiling & Concrete \\
\hline & & & Floor & Steel;paint \\
\hline & & & Wall & Concrete \\
\hline Density $\left[\mathrm{kg} / \mathrm{m}^{3}\right]$ & 1200 & 1380 & & \multirow{6}{*}{1} \\
\hline $\begin{array}{l}\text { Heat of combustion } \\
{[\mathrm{kJ} / \mathrm{kg}]}\end{array}$ & 20900 & 17974 & & \\
\hline $\begin{array}{l}\text { Heat conductivity } \\
{[W /(m \cdot K)]}\end{array}$ & 0.25 & 0.16 & & \\
\hline Ignition point [K] & 1 & 523.15 & & \\
\hline Specific heat & 1.0 & 0.9 & & \\
\hline $\begin{array}{l}\text { Heat of reaction } \\
{[\mathrm{kJ} / \mathrm{kg}]}\end{array}$ & 1 & 1500 & & \\
\hline
\end{tabular}

The room obeys the general fire compartment partitioning requirements and standards of commercial NPPs, e.g., fire barrier with a minimum fire protection endurance rating of one hour, a well-sealed concrete wall with a minimum thickness of 4 inches, spatial separation, environment condition control, etc. [1].

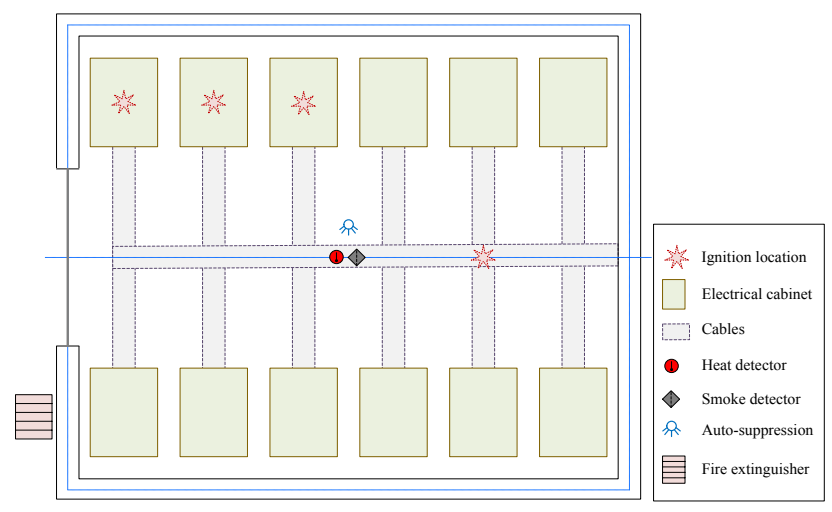

Figure 1. Layout of the switchgear room

\section{ESTIMATION OF THE DETECTION-SUPPRESSION PROBABILITY}

Regarding a fire, the non-suppression probability $P_{N S}$ is calculated by summing the probabilities of non-suppression (NS) sequences, which represent scenarios where the fire is not suppressed by the suppression protection activities, in a detection-suppression event tree. The event tree is developed by identifying the detection and suppression features installed against the fire. Three classes of (detection and suppression) protection activities are identified in the tradition detection-suppression event tree: prompt (e.g., fire watch, high sensitivity detector, etc.), automatic (e.g., heat/smoke detector, sprinkler, etc.), and delayed (manual) (e.g., control room verification, fire brigade, etc.) activities [1].

In this study, we develop the detection-suppression event tree of the switchgear room fire by: $A$. detailed fire modeling by the Fire Dynamics Simulator (FDS) [7], allowing for the estimates of the times available for the suppression actions that are feeding to calculate the probabilities of nonsuppression that suppression actions and, $B$. extracting the possibly available protection actions and developing the detection-suppression event tree.

\section{A. Detailed Fire Modeling}

FDS is here used to model $N_{F}=20$ fire scenarios for the switchgear room. Geometric parameters and physical properties values listed in TABLEs I and II, respectively are used to feed FDS.

Possible ignition sources in the simulation are assumed to be cables in the cabinets or/and in the cable trays (shown with stars in Figure 1). The fire can, then, propagate and grow in the switchgear room (under the conditions of abundant oxygen and cable ignition temperature). The FDS simulation entails:

- Obtaining the time for target damage $t_{d a m}$, (i.e., time at which the cable temperature exceeds $T_{d a m}=205^{\circ} \mathrm{C}$ (Task 8 of [1]).

- Calculating the time available for the suppression action $t_{R}$ (Appendix P of [1]): 


$$
t_{R}=t_{d a m}-t_{S}-t_{D}
$$

where, $t_{S}$ and $t_{D}$ are the response times of suppression system and of detection system, respectively (Notice that both automatic and manual suppression measures are not considered in the FDS modeling, allowing a conservative estimation of a most severe value $\left.t_{d a m}\right)$.

- Obtaining the response time of automatic detector $t_{A D}$, (triggered when the temperature of $50^{\circ} \mathrm{C}$ is exceeded and visibility becomes below $1.0 \mathrm{~m}$ due to smoke). Heat and smoke thermocouples are located as shown in Figure 1. The response time of the sprinkler $t_{A S}$ which can be obtained resorting to $t_{A S}=t_{A D}+d t_{A D}$, where $d t_{A D}$ is the delay time between automatic detection and the sprinkler actuation.

- Developing the detection-suppression event tree, considering the estimated response times of prompt, automatic and manual protection actions and the time to target damage $t_{d a m}$.

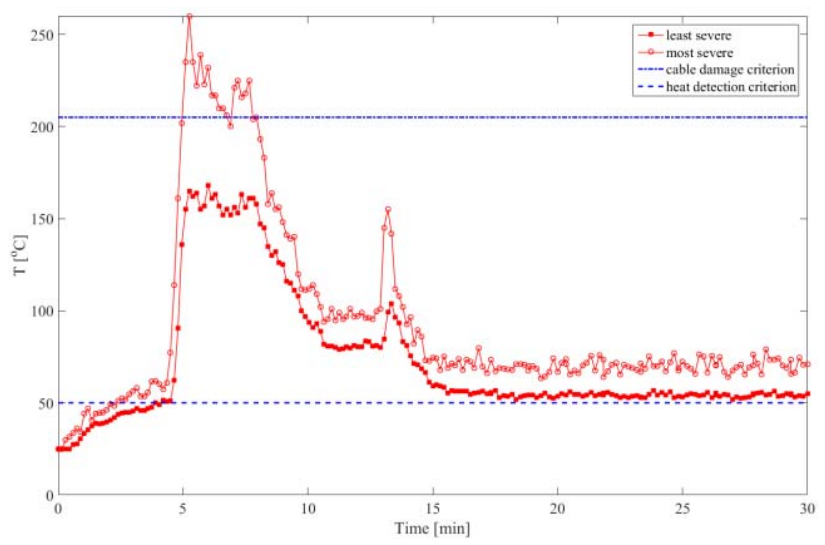

Figure 2. Profiles of the temperature of the most and the least severe fire scenarios

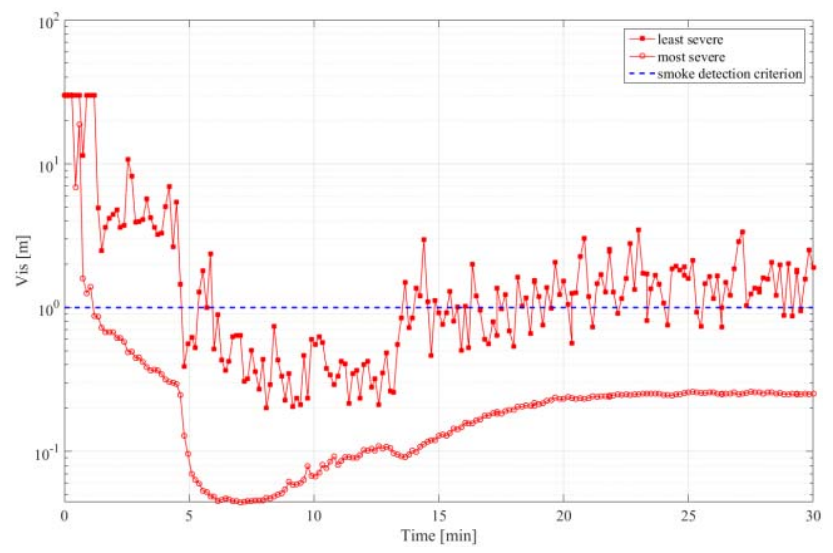

Figure 3. Profiles of the visibility of the most and the least severe fire scenarios

Figures 2 and 3 show the profiles of the temperature and the visibility of the most and the least severe FDS runs, respectively. In Figure 2, both temperature profiles remain low at the early stage of the fire scenario. Then, in the most severe scenario the fire grows rapidly and reaches the target damage criterion equal to $205^{\circ} \mathrm{C}$ at $t_{d a m}=5 \mathrm{~min}$, due to the flashover in the switchgear room. After the fully developed combustion that lasts $10 \mathrm{~min}$, the fire decays. In Figure 3 shows that in both scenarios the visibility profile rapidly decreases and goes below $1.0 \mathrm{~m}$ in a very short time period after the fire ignition. The minimum visibility lasts for around 10min, corresponding to the development of combustion in Figure 2, then smoke optical density stabilizes.

The mean value of the response time of detectors $t_{A D}$ in the $N_{R}=20$ runs of simulation are estimated by:

$$
\bar{t}_{A D}=\sum_{n=1}^{2 N_{R}} t_{A D, n} / 2 N_{R}
$$

and turns out to be equal to $3 \mathrm{~min}$. Considering the actuation of the automatic sprinkler delaying $\bar{t}_{A D}$ around 0.2 minutes (i.e., $d t_{A D}$ ), we obtain $t_{A S}$ equal to $3.2 \mathrm{~min}$.

\section{B. Development of the Detection-Suppression Event Tree}

Automatic protection actions (including responses of the heat and smoke detectors, and the automatic sprinkler) are considered in the development of the detection-suppression event tree, because they would be automatically actuated within the time to target damage, namely, $t_{d a m}>t_{A S}$.

Once detected, fire brigades are called to take prompt suppression measures to avoid the scenarios escalation. In human reliability, human performance is affected by the Performance Shaping Factors (PSFs), especially under a stressful working condition, e.g., an available time to suppression less than $5 \mathrm{~min}$. Thus, Human Error Probability (HEP) in the response of prompt protection actions should be considered in the detection-suppression event tree, accounting for the performance of an operator or a crew when acting upon an urgent event. We consider the mean values of the detection time of the fire man $t_{P D}$ and of the delay time of the fire man to get the water from the fire extinguisher $d t_{P D}$ equal to $1.5 \mathrm{~min}$ and $0.5 \mathrm{~min}$, respectively.

Manual protection actions are not considered in this study since the fire brigade (whose response time is usually at least $0.5 \mathrm{~h}[14]$ ) have no time to take any protection measures to control the switchgear room fire (with respect to the conservative $t_{\text {dam }}$ equal to $5 \mathrm{~min}$ ). In this sense, the failure probability of manual suppression action is assumed to be equal to 1 and, thus, is excluded from the detectionsuppression event tree of the switchgear room fire.

The resulting detection-suppression event tree is shown in Figure 4: 13 sequences are modeled, among which 4 allow for suppression (OK) and 9 for non-suppression (NS). In case the extinguisher (i.e., Prompt Suppression) is effectively activated by the fire man (i.e., successful Prompt Detection) or the sprinkler (i.e., Automatic Suppression) is effectively activated after received the alarm of detection (i.e., successful Automatic Detection) before $t_{d a m}$ equal to $5 \mathrm{~min}$ (i.e., successful Prompt Response or successful Automatic Response), the fire can be suppressed/mitigated (corresponding to sequences $j=1,2,6,10$ ). Whereas, in case of failures of both prompt and automatic protection actions, 
the fire cannot be successfully suppressed (corresponding to sequences $j=3,4,5,7,8,9,11,12,13$ ).

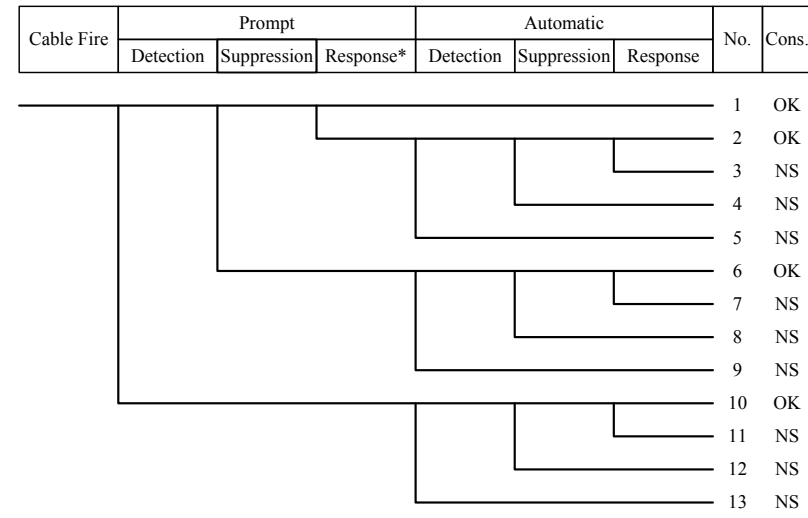

Figure 4. The detection-suppression event tree of the switchgear room fire; $(*)$ indicates that the occurrence of the event is caused by a human error

In the detection-suppression event tree of Figure 4, nine sequences contribute to the non-suppression probability. The probability of the occurrence of the $j$ th non-suppression sequence, $p_{j}, j=3,4,5,7,8,9,11,12,13$, is the product of the probabilities $P_{k}, k=P D, P S, P R, A D, A S$ and $A R$, of occurrence or non-occurrence of the events along the sequence:

$$
p_{j}=\prod_{k-\text { occurrence }} P_{k} \cdot \prod_{k-\text { non-occurrence }}\left(1-P_{k}\right)
$$

Table III lists the values of the failure probabilities of the detection and suppression protection actions (Appendix P of [1]).

\section{TABLE III. FAILURE PROBABILITIES OF THE DETECTION AND SUPPRESSION ACTIONS (APPENDIX P OF [1])}

\begin{tabular}{|l|c|}
\hline \multicolumn{1}{|c|}{ Head event } & Failure Probability \\
\hline Prompt Detection $\left(P_{P D}\right)$ & 0.1 \\
\hline Prompt Suppression $\left(P_{P S}\right)$ & 0.05 \\
\hline Automatic Detection $\left(P_{A D}\right)$ & 0.05 \\
\hline Automatic Suppression $\left(P_{A S}\right)$ & 0.05 \\
\hline
\end{tabular}

Whereas, the failure probabilities of "Prompt Response" $P_{P R}$ and of "Automatic Response" $P_{A R}$ can be calculated by the approach proposed in Appendix $\mathrm{P}$ of [1]. $P_{A R}$ that "Automatic Response" does not succeed before the time to target damage $t_{d a m}$ ) is estimated by:

$$
P_{A R}\left(t_{d a m}>t_{A R}\right)=\exp \left(-\int_{0}^{t_{A R}} \theta(s) d s\right)
$$

where $t_{A R}$ is the time available for the automatic response, $\theta\left(t_{A R}\right)$ is a function of the parameters of the probabilistic model chosen for $t_{d a m}$ and indicates a time varying the rate at which the fire is suppressed. For simplicity, $\theta\left(t_{A R}\right)$ can be estimated to be a constant value $\theta$ (assumed to be equal to 0.36 [1]) indicating the rate of fire suppressed, and Eq. (5) changes to:

$$
P_{A R}\left(t_{d a m}>t_{A R}\right)=\exp \left(-\theta t_{A R}\right)
$$

In the same way, the failure probabilities of "Prompt Response" $P_{P R}$ can be calculated by:

$$
P_{P R}=H E P \cdot \exp \left(-\theta t_{P R}\right)
$$

where, $t_{P R}$ is the time available for the prompt suppression action, and $H E P$ is the probability of human error. $t_{P R}$ and $t_{A R}$ can be calculated by Eqs. (8) and (9), respectively.

$$
\begin{aligned}
& t_{P R}=t_{d a m}-d t_{P D}-t_{P D} \\
& t_{A R}=t_{d a m}-d t_{A D}-t_{A D}
\end{aligned}
$$

In the traditional quantification of the detectionsuppression event tree of Figure 4, the headers probabilities $P_{P D}, P_{P S}, P_{A D}, P_{A S}$ are taken from TABLE IV and, whereas, $P_{P R}$ and $P_{A R}$ are calculated by Eqs. (6) and (7), in which HEP is assumed to be equal to $1 \mathrm{e}-3$ [10], and detection and suppression times $d t_{P D}, t_{P D}, d t_{A D}$ and $t_{A D}$ of Eqs. (8) and (9) are assumed to be mean values equal to $0.5 \mathrm{~min}, 1.5 \mathrm{~min}$, $0.2 \mathrm{~min}$ and $3 \mathrm{~min}$, respectively. The non-suppression probability of the switchgear room fire is estimated to be equal to 0.0828 (see dotted line with black diamonds in Fig. $10)$, based on sum of the non-suppression sequence probabilities.

\section{UnCERTAINTY PROPAGATION FOR QUANTIFYING $P_{N S}$}

\section{A. Probability Distributions of Response Times}

Among the $N_{k}$ fire scenarios of Section III.A, profile bounds allowing calculating response time intervals of the heat and smoke detector result to be $[2.5,4.5] \mathrm{min}$ and $[1$, 4.5]min, as shown in Figures 2 and 3, respectively. The deviation of the response time of detectors is estimated by:

$$
\sigma_{A D}=\sqrt{\sum_{n=1}^{2 N_{R}}\left(t_{A D, n}-\bar{t}_{A D}\right)^{2} / 2 N_{R}}
$$

and turns out to be equal to $0.64 \mathrm{~min}$. Thus, considering $\bar{t}_{A D}$ estimated equal to $3 \mathrm{~min}$, we assume the probability distribution of $t_{A D}$ follow a normal distribution $N(3,0.64)$ min. With $d t_{A D}$ being assumed to be distributed from a normal distribution $d t_{A D} \sim N(0.2,0.03) \mathrm{min}, t_{A S}$ results to be $\mathrm{N}(3.2,0.6407) \mathrm{min}$.

At the same time, we consider the probability distributions of $t_{P D}$ and of $d t_{P D}$ to be distributed from the normal distributions $N(1.5,0.5) \mathrm{min}$ and $N(0.5,0.5) \mathrm{min}$, respectively.

Table IV lists these probability distributions.

TABLE IV. DistribUtions OF THE DETECTION AND SUPPRESSION TIMES

\begin{tabular}{|l|l|}
\hline \multicolumn{1}{|c|}{ Time } & \multicolumn{1}{c|}{ Distribution } \\
\hline$t_{P D}$ & $N(1.5,0.5) \mathrm{min}$ \\
\hline$d t_{P D}$ & $N(0.5,0.5) \mathrm{min}$ \\
\hline$t_{A D}$ & $N_{A D}=N(3,0.64) \mathrm{min}$ \\
\hline$d t_{A D}$ & $d N_{A D}=N(0.2,0.03) \mathrm{min}$ \\
\hline
\end{tabular}




\section{B. Possibility Distributions of HEP}

In Human Reliability Analysis (HRA), HEP is incorporated into the overall probabilistic models [9]. The SPAR-H method can be used to quantify the HEP by providing a taxonomy of common human errors (i.e., PSFs) under expert judgment [10]. In this study, HEP is estimated by the SPAR-H method, to calibrate the failure probability of the "Prompt Response". Due to the scarcity of data, possibility distributions are here proposed to represent epistemic uncertainty in the SPAR-H model [5].

A possibility distribution $\pi(y)$ describes the more or less plausible values of epistemic uncertain variable $y$, and provides two measures of the likelihood of an event, for instance that the value of a real variable $y$ should lie within a certain interval $A$ : the possibility $\mathrm{S}$ and the necessity $\mathrm{N}$.

$$
\begin{gathered}
S(A)=\sup _{y \in A} \pi(y) \\
N(A)=1-S(\bar{A})=\inf _{y \notin A}(1-\pi(y))
\end{gathered}
$$

With respect to the representation of uncertainty, one resorts to the elicitation of expert knowledge that is often of ambiguous, qualitative nature so that the associated uncertainty may be more adequately captured by possibilistic distributions.

Table $\mathrm{V}$ lists the eight basic PSFs that are used to estimate the HEP [10].

TABLE V. PSFs UTILIZED IN THE SPAR-H MODEL [10]

\begin{tabular}{|l|l|}
\hline \multicolumn{1}{|c|}{ PSF $_{\mathbf{i}}$} & \multicolumn{1}{c|}{ Definition } \\
\hline $\begin{array}{l}\text { Available } \\
\text { time }\end{array}$ & $\begin{array}{l}\text { The amount of time that an operator or a crew has } \\
\text { to diagnose and act upon an abnormal event. }\end{array}$ \\
\hline Stress & $\begin{array}{l}\text { The level of undesirable conditions and } \\
\text { circumstances that impede the operator from easily } \\
\text { completing a task. }\end{array}$ \\
\hline Complexity & $\begin{array}{l}\text { How difficult the task is to perform in the given } \\
\text { context. }\end{array}$ \\
\hline $\begin{array}{l}\text { Experience/ } \\
\text { training }\end{array}$ & $\begin{array}{l}\text { The experience and training of the operator(s) } \\
\text { involved in the task. }\end{array}$ \\
\hline Procedure & $\begin{array}{l}\text { The existence and use of formal operating } \\
\text { procedures for the tasks under consideration. }\end{array}$ \\
\hline Ergonomics & $\begin{array}{l}\text { The equipment, displays and controls, layout, } \\
\text { quality and quantity of information available from } \\
\text { instrumentation, and the interaction of the } \\
\text { operator/crew with the equipment to carry out } \\
\text { tasks. }\end{array}$ \\
\hline $\begin{array}{l}\text { Fitness for } \\
\text { duty }\end{array}$ & $\begin{array}{l}\text { Whether or not the individual performing the task } \\
\text { is physically and mentally fit to perform the task at } \\
\text { the time. }\end{array}$ \\
\hline $\begin{array}{l}\text { Work } \\
\text { processes }\end{array}$ & $\begin{array}{l}\text { Aspects of doing work, including inter- } \\
\text { organizational, safety culture, work planning, } \\
\text { communication, and management support and } \\
\text { policies. }\end{array}$ \\
\hline
\end{tabular}

The product of all the PSFs is, then, used to calculate the HEP, as in Eqs. (13) and (14):

$$
P S F_{\text {composite }}=\prod_{i} P S F_{i}
$$

$$
H E P=\frac{N H E P \cdot P S F_{\text {composite }}}{N H E P \cdot\left(P S F_{\text {composite }}-1\right)+1}
$$

where $N H E P$ is the nominal $H E P$ value that sometimes can be cited from the database; and $P S F_{\text {composite }}$ of Eq. (13) is the composite PSF that accounts for a combined influence that all PSFs in the SPAR-H model jointly result in. Each PSF is assigned with a PSF level (value) from a couple of options by the reviewer judgment.

Interdependencies among PSFs affecting the "Prompt Response" event are represented by the PSF influence matrix (Appendix G of [10]) shown in Figure 5. Accordingly, the experts elicit their knowledge on the possibility distributions of the PSFs, i.e., $\pi\left(\mathrm{PSF}_{i}\right), i=\mathrm{av}($ ailable time), st(ress), co(mplexity), ex(perience/training), pr(ocedure), er(genomics), fi(tness for duty) and wo(rk processes), as shown in Figure 6, to represent the multipliers of the PSFs affecting the human performance in "Prompt Response".

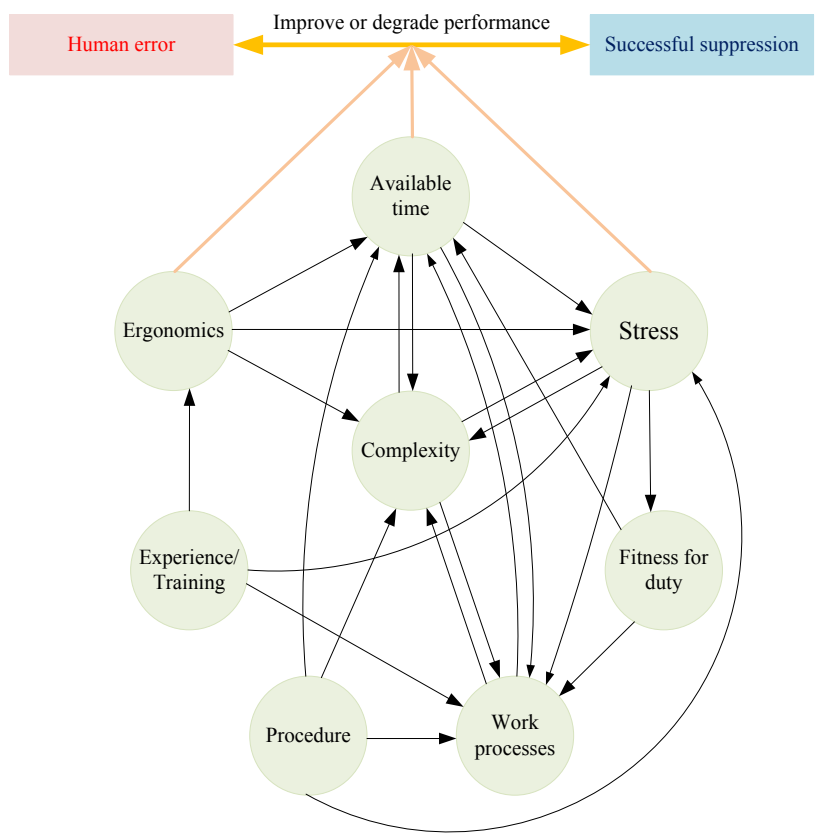

Figure 5. Path diagram showing the interdependencies among PSFs affecting the human performance in the event "Prompt Response"

Without loss of generality, we have considered $20 \alpha$-cuts $\left[\underline{\pi}^{\alpha}\left(P S F_{i}\right), \bar{\pi}^{\alpha}\left(P S F_{i}\right)\right]$ with $\alpha \quad(=0.05, \quad 0.1, \ldots, 1)$ to characterize each $i$ th possibility distribution $\pi\left(\mathrm{PSF}_{i}\right)$ of Figure 6. By using the fuzzy extension principle ([3, 5, 15, $16])$, the $\alpha$-cuts of the possibility distribution describing the quantity $P S F_{\text {composite }}$ of Eq. (13) are computed.

$$
\begin{aligned}
{\underline{P S F_{\text {composite }}^{\alpha}}}^{\alpha}=\prod_{i} \pi^{\alpha}\left(P S F_{i}\right) \\
\overline{P S F}_{\text {composite }}^{\alpha}=\prod \bar{\pi}^{\alpha}\left(P S F_{i}\right)
\end{aligned}
$$



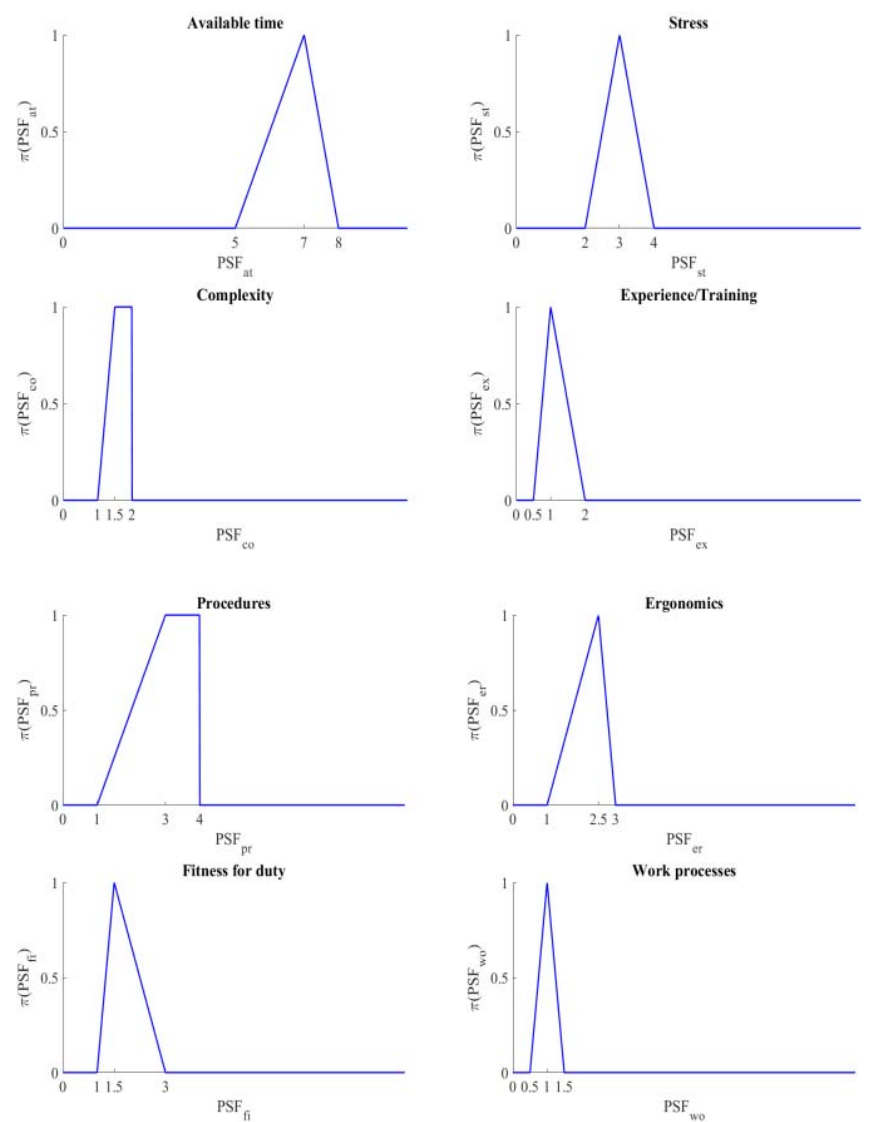

Figure 6. Possibility distributions of the eight PSFs affecting the human performance in the event "Prompt Response"

Figure 7 shows the obtained possibility distributions of $P S F_{\text {composite. }}$ Then, the possibility distribution of the HEP is computed by applying the extension principle to Eq. (14). And using a $N H E P$ value equal to $1 \mathrm{e}-3$ according to [10], Figure 8 shows the obtained results.

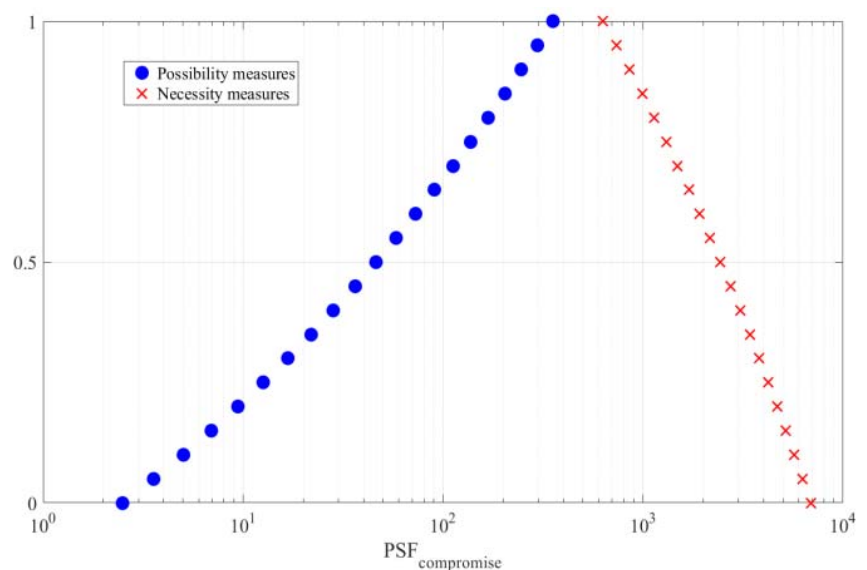

Figure 7. Lower and upper limits of the $\alpha$-cut of $P S F_{\text {composite }}$

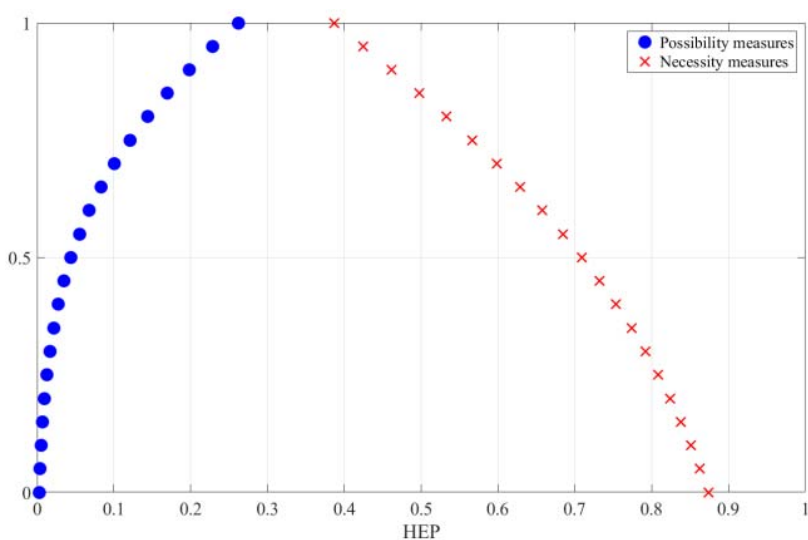

Figure 8. Lower and upper limits of the $\alpha$-cut of HEP

\section{Results}

The non-suppression probability of the detectionsuppression event tree of Figure 4 can be estimated, combined with $N_{m}=100$ runs of MC. At each run,

1) Sample the values of the detection and suppression times from the probability distributions of TABLE IV, then, to calculate $P_{P R}$ without considering $H E P$ and $P_{A R}$;

2) Integrate the lower and upper limits of the $\alpha$-cut of $H E P\left[\underline{H E P}^{\alpha}, \overline{H E P}^{\alpha}\right]$ into $P_{P R}$, to calculate the $\alpha$-cut intervals of PPR $\left[\underline{P}_{P R}^{\alpha}, \bar{P}_{P R}^{\alpha}\right]$;

3) Calculate the probabilities $(j=7,8,9,11,12,13)$ and the $\alpha$-cut intervals $(j=3,4,5)$ of the occurrence of the nonsuppression sequences based on Eq. (4), and, thus, sum into the $\alpha$-cut intervals of non-suppression probability;

4) Calculate the mean values of the $\alpha$-cut intervals of non-suppression probability $\left[\underline{P}_{N S}^{\alpha}, \bar{P}_{N S}^{\alpha}\right]$, by repeating Steps 1) to 3$)$ for $N_{m}$ times and collecting the related statistics.

Figure 9 shows the $\alpha$-cut intervals of the probability of the successful suppression $(j=1,2)$ and non-suppression $(j=3,4,5)$ sequences, which are attributed to the possibility distribution of HEP of the "Prompt Response". The probabilities of these sequences are characterized by the $\alpha$ cut intervals between the lower and the upper limits, and affected by the distributions obtained from the detailed fire modeling and from the human reliability analysis. The remainder of the sequences is not affected by the possibility distribution of HEP, since the "Prompt Response" is failed. For each trial of the MC simulation, the probabilities of the sequences can be calculated by Eq. (4).
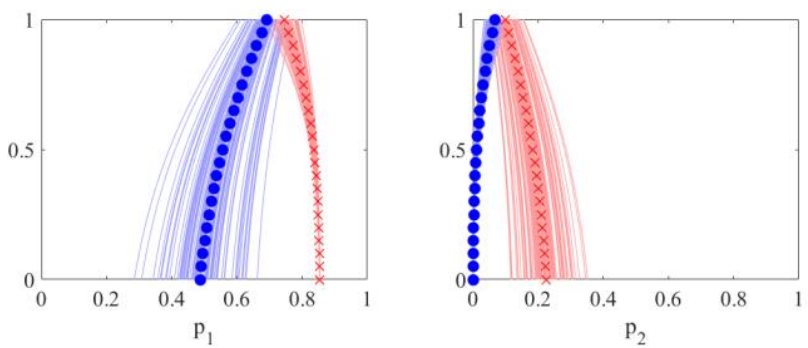


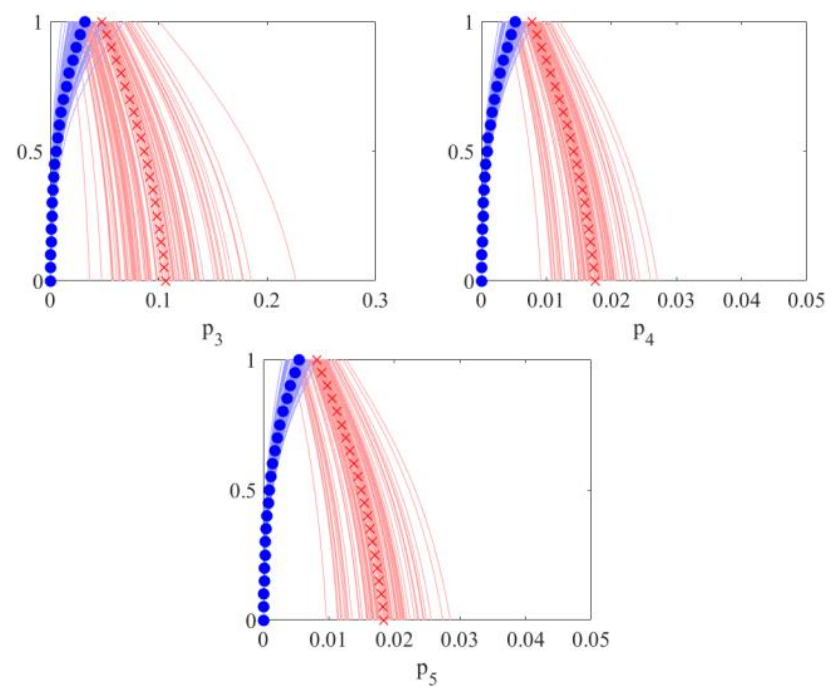

Figure 9. The $\alpha$-cut intervals of the occurrence of the suppression $(1,2)$ and non-suppression $(j=3,4,5)$ sequences

Figure 10 shows all the $N_{m}$ trials of the estimated $\alpha$-cut intervals of the non-suppression probability such that the mean values $\left[\underline{\mathrm{N}}_{\mathrm{NS}}^{\alpha}, \overline{\mathrm{P}}_{\mathrm{NS}}^{\alpha}\right]$ can be obtained, combining the $\alpha$-cut intervals of the occurrence of the non-suppression $(j=3,4,5)$ sequences with the probabilities of occurrence of the sequences which are not affected by HEP $(j=7,8,9,11,12$, 13). The non-suppression probability is characterized by the $\alpha$-cut intervals between the lower and the upper limits, and affected by both the probabilistic and possibilistic estimates obtained from the detailed fire modeling and from the human reliability analysis. Results show that the preference of the non-suppression probability is between 0.0993 and 0.1538 where the degree of possibility is equal to 1 , whereas the $\alpha$ cut intervals are increasing when the degrees of possibility are small. The reason is that the estimated HEP is the product of all the PSFs with a relative large $\alpha$-cut intervals, such that will entail further minimization of the possibility distribution, based on the identification of the interrelations among PSFs and the most critical PSFs affecting the "Prompt Response".

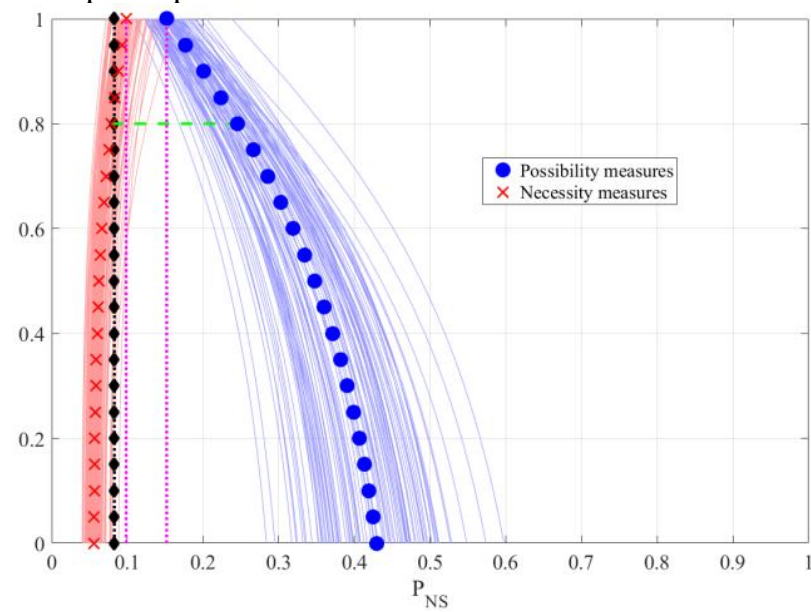

Figure 10. The $\alpha$-cut intervals of the non-suppression probability
As comparison, conservative result of the traditional estimation $\left(P_{N S}\right.$ equal to 0.0828$)$ drops into the $\alpha$-cut intervals between possibility and necessity measures when $\alpha$ $\leqslant 0.8$, whereas, it is illustrated to be underestimated, combined with the preference interval between 0.0993 and 0.1538 when $\alpha=1.0$ obtained from Figure 4, without considering aleatory uncertainty of automatic protection actions and epistemic uncertainty of human behavior. These results highlight that neglecting a proper treatment and propagation of epistemic uncertainty related to human behavior would endanger the NPP, due to an underestimation of the non-suppression probability.

\section{CONCLUSIONS}

In this study, a hybrid Monte Carlo (MC) and possibilistic approach is proposed for uncertainty propagation responding to a fire, to estimate the nonsuppression probability by quantifying the detectionsuppression event tree.

The proposed approach is applied to a fire scenario of a NPP switchgear room. Aleatory uncertainties represented by probability distributions is obtained from a FDS detailed fire modeling that simulates the fire growth and propagation processes, whereas epistemic uncertainties represented by the possibility distributions is empirically judged by a SPAR-H method where the probability of human error is characterized by the product of eight basic human PSFs.

The resulting preference of the non-suppression probability combining the considered probabilistic and possibilistic variables is between 0.0993 and 0.1538 and, provides a better and more realistic estimation compared with the traditional probabilistic approach. However, a relative large $\alpha$-cut intervals of the non-suppression probability at the small degrees of possibility will raise further concerns on optimization of the estimation of the variable distributions, especially for the possibility distributions of PSFs in the SPAR-H model, where the most critical PSFs affecting the "Prompt Response" should be identified, to assess the quantitative interrelations among PSFs and, thus, to more conservatively estimate the HEP and the non-suppression probability.

\section{REFERENCES}

[1] Electric Power Research Institute (EPRI) \& Division of Risk Analysis and Applications Office of Nuclear Regulatory Research (RES) of U. S. Nuclear Regulatory Commission (NRC), EPRI/NRC-RES Fire PSA Methodology for Nuclear Power Facilities, Final Report (EPRI 1011989, NUREG/CR-6850). Washington, DC, 2005.

[2] G. Vinod, R. K. Saraf, A. K. Ghosh, H. S. Kushwaha, and Sharma PK, "Insights from fire PSA for enhancing NPP safety," Nuclear Engineering and Design, vol. 238(9), pp. 2359-68, 2008.

[3] P. Baraldi, and E. Zio, "A combined Monte Carlo and possibilistic approach to uncertainty propagation in event tree analysis. Risk Analysis," vol. 28(5), pp. 1309-1326, 2008.

[4] M. Kloos, and J. Peschke, "Improved Modelling and Assessment of the Performance of Firefighting Means in the Frame of a Fire PSA," Science and Technology of Nuclear Installations, vol. 2015, Article ID 238723, 10 pages, 2015. doi:10.1155/2015/238723

[5] P. Baraldi, I. C. Popescu, and E. Zio, "Methods of Uncertainty Analysis in prognostics," International Journal of Performability Engineering, vol. 6(4), pp. 303-330, 2010. 
[6] R. Flage, P. Baraldi, E. Zio, and T. Aven, "Probability and PossibilityBased Representations of Uncertainty in Fault Tree Analysis," Risk Analysis, vol. 33(1), pp. 121-133, 2013.

[7] K. McGrattan, S. Hostikka, R. McDermott, J. Floyd, C. Weinschenk, and K. Overholt, Fire dynamics simulator, user's guide. NIST special publication 1019, 2014.

[8] Y. Yu, N. Ma, Y. Peng, X. Lv, F. Niu, and X. Du, "Fire risk analysis based on one-dimensional model in nuclear power plant," Annals of Nuclear Energy, vol. 94, pp. 409-414, 2016.

[9] R. L. Boring, and D. I. Gertman, "Advancing usability evaluation through human reliability analysis," In Proceedings of HCI International 2005, 2005.

[10] D. Gertman, H. Blackman, J. Marble, J. Byers, and C. Smith, The SPAR-H human reliability analysis method (NUREG/CR-6883; INL/EXT-05-00509). US Nuclear Regulatory Commission, Washington, DC, 2005.

[11] P. Liu, and Z. Li, "Human Error Data Collection and Comparison with Predictions by SPAR-H," Risk Analysis, vol. 34(9), pp. 17061719, 2014.

[12] W. Wang, J. J. Tong, and J. Zhao, "Application of NUREG/CR-6850 to the Fire Risk Quantification of a High Temperature Gas-Cooled Reactor," Nuclear Engineering and Design, under review.

[13] G. Ripamonti, G. Lonati, P. Baraldi, F. Cadini and E. Zio, Uncertainty propagation in a model for the estimation of the ground level concentration of dioxin/furans emitted from a waste gasification plant. Reliability Engineering \& System Safety, 120, pp.98-105, 2013.

[14] S. Einarsson, M. Tuerschmann, and M. Roewekamp, "Event Tree Methodology as Analytical Tool for Fire Events," Probabilistic Safety Assessment and Management PSAM 12, Honolulu, Hawaii, June 2014.

[15] T. Aven, E. Zio, P. Baraldi, and R. Flage, Uncertainty in risk assessment: the representation and treatment of uncertainties by probabilistic and non-probabilistic methods. John Wiley \& Sons, 2013.

[16] C. Baudrit, D. Dubois, and D. Guyonnet, Joint propagation and exploitation of probabilistic and possibilistic information in risk assessment. IEEE transactions on fuzzy systems, 14(5), pp.593-608, 2002.

[17] N. Melly, et al., Refining and Characterizing Heat Release Rates From Electrical Enclosures During Fire (RACHELLE-FIRE), Volume 1: Peak Heat Release Rates and Effect of Obstructed Plume, NUREG2178. USNRC, 2015.

[18] C. Worrell, R. Schneider, B. Leyde and M. Xu, Emulation-Based Uncertainty Quantification of a Fire Dynamics Simulation. In ANS International Topical Meeting on Probabilistic Safety Assessment and Analysis (PSA 2017), Pittsburgh, PA, September 24-28, 2017. 